\title{
Evaluation of Asian Dust Absorption in Visible Band with Satellite Observation, Sky-radiometer Measurement, and Chemical Transport Model
}

\author{
Yuichiro Hagihara ${ }^{1 *}$, Hajime Fukushima ${ }^{1}$, Itsushi Uno ${ }^{2}$, and Sachio Ohta ${ }^{3}$ \\ ${ }^{1}$ School of High-Technology for Human Welfare, Tokai University, Numazu, Japan \\ ${ }^{2}$ Research Institute for Applied Mechanics, Kyushu University, Fukuoka, Japan \\ ${ }^{3}$ Graduate School of Engineering, Hokkaido University, Sapporo, Japan
}

\begin{abstract}
We assessed the spectral imaginary part of refractive index $\left(n_{\mathrm{i}}\right)$ of Asian dust aerosol in the visible wavelengths $(0.412-0.865 \mu \mathrm{m})$ by comparing simulated and satelliteobserved top of the atmosphere (TOA) reflectances. The approach employed in this study combines the results obtained from SeaWiFS ocean color sensor, the vertical profiles provided by CFORS mesoscale transport model, and the size distribution observed concurrently by Aerosol Robotic Network (AERONET) sites. Analyses for four dust instances over the Sea of Japan during 2001 and 2002 showed that the $n_{\mathrm{i}}$ values of Asian dust are significantly lower than previously published, as low as about 0.001 at $0.5 \mu \mathrm{m}$. Although the backward trajectories suggest that the four events have different sources, all events show very similar $n_{\text {i }}$ values. The corresponding averaged coarse-mode dust single-scattering albedo (SSA) is found to be $0.98 \pm$ 0.002 at $0.555 \mu \mathrm{m}$, which is consistent with the results of several contemporaneous observations conducted during Asian Aerosol Characterization Experiment (ACE-Asia). These results indicate that Asian dust particles itself may cool the climate system more strongly than is generally considered and a weakly absorbing model of Asian dust is more appropriate for use in climate modeling than the already used dust model.
\end{abstract}

\section{Introduction}

Asian dust has a significant impact on the Earth's radiation budget by scattering and absorbing solar radiation. Hence, determination of the optical properties of Asian dust is indispensable for improving climate assessments. Development of algorithms for aerosol and ocean color remote sensing also requires precise knowledge of the optical properties of Asian dust (Fukushima and Toratani 1997; Higurashi and Nakajima 2002).

From remote sensing observations (Kaufman et al. 2001; Dubovik et al. 2002), it is generally agreed that Saharan dust has much lower absorption in the visible part of spectrum than previously assumed (Patterson 1981; WMO 1983; Hess et al. 1998). On the other hand, surface observations of Asian dust (Nakajima et al. 2003; Kim et al. 2005) report a high absorption with single-scattering albedo (SSA) values ranging from 0.80 to 0.86 at $0.5 \mu \mathrm{m}$ which is considered due to the co-existing absorbing anthropogenic aerosols produced over the industrial area of China. The mixing states of industrial pollution and Asian dust, however, are highly variable and Asian dust absorption still remains unknown.

In this study we attempt to estimate the spectral dependency of imaginary part of refractive index $\left(n_{\mathrm{i}}\right)$ for Asian dust in the visible wavelength region by comparing simulated and satellite-observed top of the atmosphere (TOA)

Corresponding author: Yuichiro Hagihara, School of HighTechnology for Human Welfare, Tokai University, Numazu, 410-0395, Japan. E-mail: hagihara@caos-a.geophys.tohoku.ac.jp. *Present affiliation: Graduate School of Science, Tohoku University, Sendai, Japan. @2006, the Meteorological Society of Japan.

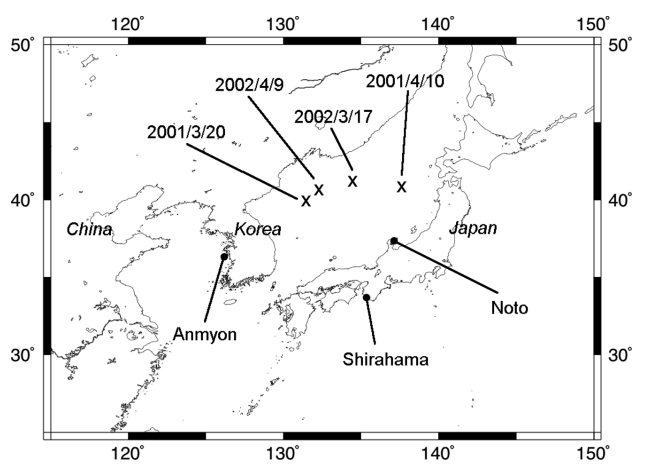

Fig. 1. Geographic locations of the observation points. The cross symbols indicate the SeaWiFS TOA reflectance sampling points. The solid circles indicate the location of AERONET sites.

reflectances. We make use of data obtained by SeaStar/ SeaWiFS, an ocean color instrument that has wellcalibrated visible spectral bands to infer spectra of the imaginary part. To simulate the SeaWiFS-observed reflectances, we model the aerosol size distribution and vertical profile after Aerosol Robotic Network (AERONET) and Chemical Weather Forecasting System (CFORS), respectively. As a base reference for the imaginary part of the refractive index for Asian dust, we adopted those values obtained by a laboratory measurement of soil particles in China to perform radiative transfer simulation with adjusting aerosol optical thickness (AOT) of Asian dust so that it reproduces the satellite observed TOA reflectance at $0.865 \mu \mathrm{m}$.

\section{Method and data}

The SeaWiFS has eight spectral bands in the visible $(0.412,0.443,0.490,0.510,0.555,0.670,0.765$, and $0.865 \mu \mathrm{m})$ (Hooker et al. 1992). The accuracy of the radiometric calibration of SeaWiFS is considered to be within $\pm 3 \%$ (F. S. Patt, personal communication). We selected four Asian dust-prevailing air masses over the Sea of Japan observed on 20 March 2001, 10 April 2001, 17 March 2002, and 9 April 2002, which displayed most intense dust transport. For each event, we extracted TOA reflectances and scan geometry from the $15 \times 15$ pixels in the center of the dust plume. The sampling points are shown in Fig. 1.

Radiative transfer (RT) simulations were conducted for each sampling point using Rstar5b code developed by Nakajima and Tanaka $(1986,1988)$. Here water reflectance is neglected, because, its effect is not significant to TOA reflectances with dense Asian dust air mass. We assumed aerosol consisting of two species, Asian dust and sulfate aerosols, since the amount of other species is predicted negligibly small for all events (Fig. 2).

We used the following procedures to determine models and parameters in this simulation. Firstly, the refractive indices for the two species were modeled as follows. For sulfate aerosol, we simply adopted the values modeled by Shettle and Fenn (1979). For dust aerosol, we derived the 


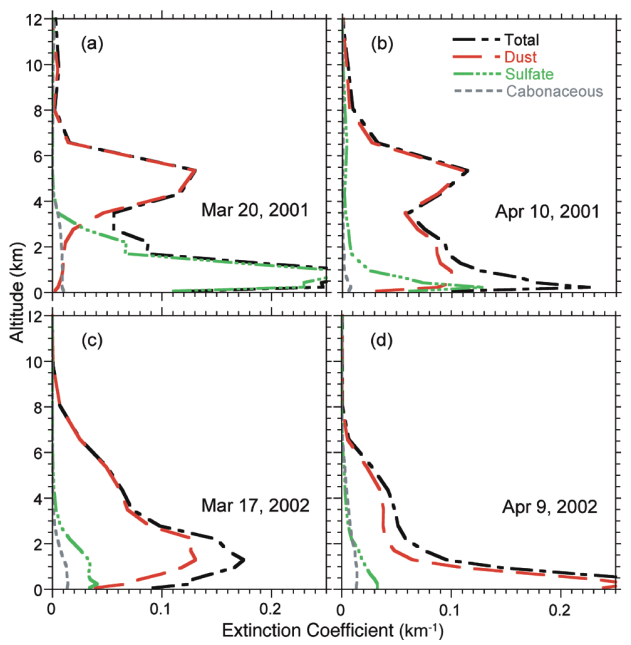

Fig. 2. Vertical profiles of extinction coefficient predicted by the CFORS

refractive index based on the optical measurement of the soil particles sampled at the loess layer $(1.8-2.5 \mathrm{~m}$ from the surface) in Gansu Province in China. The real part of the index was determined as 1.51. The imaginary part was obtained by measuring absorption of the soil particles using an integrating sphere (see Fig. 4, Ohta 2002 model). The dust particles were assumed to be non-spherical, based on the semi-empirical model of Pollack and Cuzzi (1980), where the values of three non-sphericity scattering parameters $\chi_{0}, \gamma$, and $G$ were set to be $1.1,7$, and 10 as modeled by Nakajima et al. (1989).

Secondly, the aerosol size distribution was provided by the AERONET (Holben et al. 2001) observation sites at Noto (37N, 137E), Anmyon (37N, 126E), and Shirahama (34N, 135E) (see Fig. 1). Approximating the size spectrum by bi-modal lognormal distribution, we assumed that the coarse mode particles consist of Asian dust while the fine mode particles consist of sulfate. An expected accuracy of AERONET-derived volume size distribution is generally estimated to be $15-25 \%$ for mode radius $\left(r_{\mathrm{m}}\right) \geq 0.5 \mu \mathrm{m}$ and $25-100 \%$ for $r_{\mathrm{m}}<0.5 \mu \mathrm{m}$ (Dubovik et al. 2000).

Thirdly, the aerosol vertical profiles were modeled after the predicted results by CFORS mesoscale transport model (Uno et al. 2003). The CFORS-derived aerosol profile generally compares well with lidar observations (i.e., Shimizu et al. 2004).

Finally, we conducted RT simulation with adjusting AOT of the model Asian dust so that the simulated TOA reflectance at $0.865 \mu \mathrm{m}$ reproduces the satellite observed one, while the AOT of sulfate was kept the same as the CFORSpredicted AOT.

\section{Results}

The aerosol volume size distributions were derived

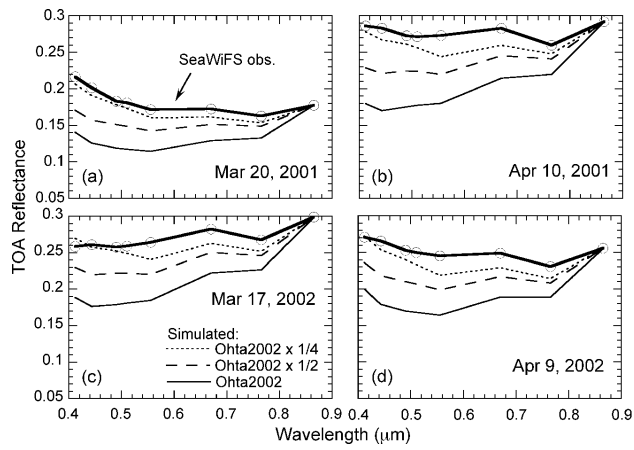

Fig. 3. TOA spectral reflectance over the Sea of Japan measured by SeaWiFS (thick line). The measurements are compared with three calculations (thin lines). The solid line corresponds to the imaginary part of the refractive index of Asian dust (see Fig. 4). The dashed line corresponds to the imaginary part value reduced to half. The dotted line corresponds to the imaginary part value reduced to one-fourth.

from AERONET observations made on the same day with the satellite overpass except the case of 17 March 2002 where the data obtained on the next day was used. The vertical profiles of aerosol extinction coefficient predicted by the CFORS for all events are shown in Fig. 2, which, as mentioned earlier, shows that contribution of carbonaceous aerosol is very low. The parameters of volume size spectrum, namely $C_{\mathrm{v}}$, the column volume, $\sigma_{\mathrm{gv}}$, the standard deviation and the vertical profile of each aerosol modeled by the CFORS for the four events are summarized in Table 1.

Figure 3 shows the SeaWiFS-observed and the TOA reflectances for all events. It is obvious that the simulated TOA reflectances in the shorter wavelength bands are much smaller compared to those observed by SeaWiFS. The simulated results obtained by assuming half, and onefourth of the original values of $n_{\mathrm{i}}$, are also shown in Fig. 3. We found that the $n_{\text {i }}$ value reduced to one-fourth well explains SeaWiFS observations. It is interesting to note that similar results are obtained through all the four events. Figure 4 presents a comparison of the retrieved results in this analysis and the results obtained by others. The $n_{\mathrm{i}}$ values from OPAC Mineral are mineral dust model in OPAC 3.1 (Hess et al. 1998) and those from Patterson (1981) are from laboratory measurements of Saharan dust, both of them indicating high absorption like 0.008 at $0.5 \mu \mathrm{m}$ by the WMO (1983). Aoki et al. (2005) derived $n_{\mathrm{i}}$ value from the measurements of solar irradiance spectrum on the groundbased observation in the Taklimakan region, indicating 0.0041 at $0.5 \mu \mathrm{m}$. Moulin et al. (2001) published the $n_{\mathrm{i}}$ value from comparing simulated and observed aerosol reflectance of Saharan dust air mass.

The average coarse-dust SSA spectra obtained for two values of $n_{\mathrm{i}}$, the original and one-fourth values, are presented in Fig. 5. The error bars are the standard deviation of the retrieved SSA where variability comes from the different size distributions for four events studied. While the SSA obtained for the original $n_{\mathrm{i}}$ value is $0.92 \pm 0.008$ at

Table 1. Model parameters of aerosol volume size distribution at the AERONET sites and the profiles of the aerosols modeled after CFORS prediction used in the RT simulation.

\begin{tabular}{|c|c|c|c|c|}
\hline & $\begin{array}{c}\text { Anmyon } \\
(2001 / 3 / 20)\end{array}$ & $\begin{array}{c}\text { Noto } \\
(2001 / 4 / 10)\end{array}$ & $\begin{array}{c}\text { Shirahama } \\
(2002 / 3 / 18)\end{array}$ & $\begin{array}{l}\text { Shirahama } \\
(2002 / 4 / 9)\end{array}$ \\
\hline \multicolumn{5}{|l|}{ fine mode $(r<0.6 \mu \mathrm{m})$} \\
\hline$r_{\mathrm{m}}(\mu \mathrm{m})$ & 0.109 & 0.082 & 0.200 & 0.090 \\
\hline$\sigma_{g v}$ & 1.696 & 1.618 & 1.716 & 1.699 \\
\hline$C_{\mathrm{v}}$ & 0.161 & 0.154 & 0.059 & 0.120 \\
\hline vertical profiles $(\mathrm{km})$ & $0-1$ & $0-1$ & $0-1$ & $0-1$ \\
\hline \multicolumn{5}{|l|}{ coarse mode $(r>0.6 \mu \mathrm{m})$} \\
\hline$r_{\mathrm{m}}(\mu \mathrm{m})$ & 2.937 & 1.682 & 1.780 & 1.990 \\
\hline$\sigma_{\mathrm{gv}}$ & 1.877 & 1.684 & 2.075 & 1.804 \\
\hline$C_{\mathrm{v}}$ & 0.375 & 0.265 & 0.082 & 0.345 \\
\hline vertical profiles $(\mathrm{km})$ & $4-6$ & $0-6$ & $0-3$ & $0-1$ \\
\hline
\end{tabular}




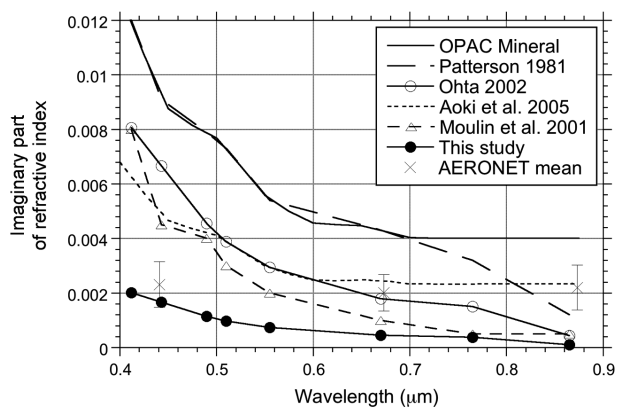

Fig. 4. Imaginary part of the refractive index of Asian dust retrieved in this study in comparison with other models including general "mineral dust" models. The cross symbols stands for mean values of three events derived from AERONET (except 17 March 2002). The thin line shows the original Ohta model. The dotted line shows the Aoki et al. (2005). The dashed line shows the Patterson (1981).

$0.555 \mu \mathrm{m}$, the one for the one-fourth $n_{\mathrm{i}}$ case significantly increased to $0.98 \pm 0.002$.

\section{Discussion}

We see from Fig. 3 that the $n_{\text {i }}$ value reduced to onefourth of the lab-measured one well explains SeaWiFS observations. The difference between the simulated and satellite-derived reflectance may be explained by too large $n_{\mathrm{i}}$ values used in this simulation for the dust. As seen in Fig. 4 , comparison of $n_{\mathrm{i}}$ values showed similar spectral dependency although they are different in the absolute values. Recent observations of Asian and Saharan dust revealed that the particles are much less absorbing compared to Patterson (1981). The discrepancies may be explained by the fact that dust particles observed around Japan often get coated with sea salt and other soluble compounds (Zhou et al. 1996; Trochkine et al. 2003), suggesting that the contamination on dust particles may reduce their ability to absorb the visible radiation. The results of this study and the AERONET mean are consistent in shorter wavelength bands, whereas the AERONET-derived values are about 0.002 higher in longer wavelength region. This difference can be explained by the presence of ground-level pollution or carbonaceous aerosol observed by AERONET due to the relatively constant imaginary part of refractive index of black carbon.

It may be noted that the locations of the study points are significantly away from the AERONET sites. Whereas we recognize the potential difference in the size distribution between at Shirahama and at the observation points, our sensitivity study for 9 April 2002 case shows that \pm 0.5 $\mu \mathrm{m}$ uncertainty in the coarse mode radius produces errors of \pm 0.0005 at $0.5 \mu \mathrm{m}$ in the retrieved imaginary part of refractive index of Asian dust. Thus the result does not affect our conclusion that Asian dust is much less absorbing in the visible than previously mentioned.

The SSA is the important indicator for aerosol climate effects since a low SSA will lead a warming effect, while a high one will behave vice versa. The coarse-mode SSA simulated for the one-fourth of the ground-sampled $n_{\mathrm{i}}$ value is significantly higher than the original case (Fig. 5). The result suggests a weakly absorbing model of Asian dust is more appropriate for use in climate modeling than the previously assumed dust model; in other words Asian dust particles may cool the climate system more strongly than is generally believed. Except the case of 17 March 2002, the events mean values of coarse mode SSA derived from the AERONET are 0.05 lower than the ones from this study, corresponding to the higher value of the imaginary part retrieved by the AERONET. To validate, we have also plotted in Fig. 5 several other coarse-mode SSA observed in the East Asian region during Asian Aerosol Characterization Experiment (ACE-Asia) (Huebert et al. 2003). The

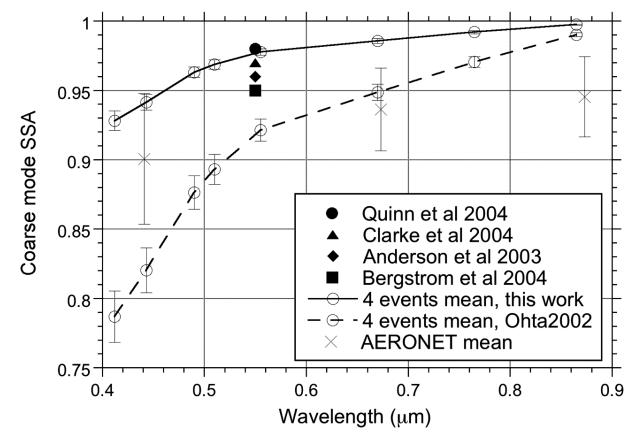

Fig. 5. Averaged SSA of Asian dust as a function of the wavelength on the four events.

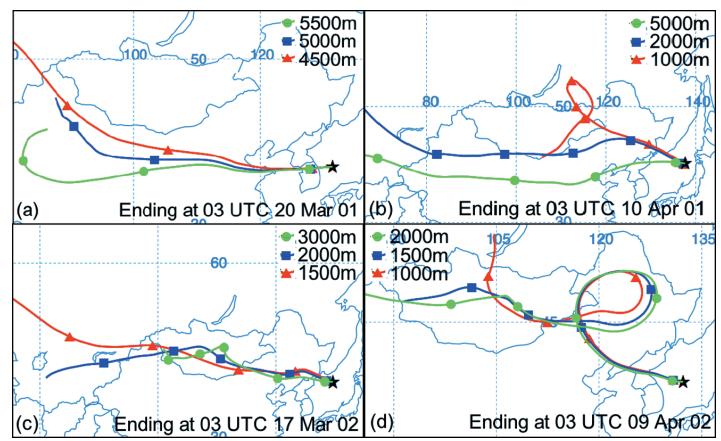

Fig. 6. Backward air trajectories for each sampling points.

coarse-mode SSA from Quinn et al. (2004) are from the PSAP on board the R/V Ronald $H$. Brown, those from Clarke et al. (2004) are from the PSAP results for dust extracted volatile components aboard the C-130, those from Anderson et al. (2003) are from the PSAP results observed aboard the $\mathrm{C}-130$, and those from Bergstrom et al. (2004) are from the measurement of the solar flux observed aboard the Twin Otter. Figure 5 shows that the coarsemode SSA simulated for the one-fourth $n_{\mathrm{i}}$ value is in good agreement with other results.

On the other hand, recent observations reported that Asian dust has a high absorption in the Japan area (Nakajima et al. 2003; Kim et al. 2005). It is believed that the fine $\mathrm{BC} /$ pollution particles that accompanied the dust reduce the SSA though coarse-mode dust particles itself did not have high absorption (Anderson et al. 2003; Bergstrom et al. 2004; Clarke et al. 2004). We conjecture that the coarse-mode SSA retrieved in this study is realistic because the contributions of carbonaceous are very low for all the four events (Fig. 2).

It may be considered that dust from different source regions have different optical properties. Air mass backward trajectories for TOA sampling points were conducted with Hybrid Single-Particle Lagrangian Trajectory (HYSPLIT, NOAA/ARL) (Draxler 1996) (Fig. 6). The Final Run (FNL) meteorological data, or 6-hourly archive data from National Centers for Environmental Prediction's Global Data Assimilation System (GDAS), were used for the trajectory calculation. In the two cases of 2001 (Fig. 6a and $6 \mathrm{~b})$, cold air outbreaks from the west resulted in dust storms in the Taklimakan Desert in western China. In the third and fourth cases of 2002, cold air coming from the northwest and north caused dust storms in the Gobi Desert of Mongolia, illustrated in Fig. 6c and 6d. Although in this study the dust events originated from different sources, all events show same low absorption (Fig. 3). Therefore, the dust absorption properties may not depend strongly on their source regions. This is consistent with the measurements of SSA at East Asia (Uchiyama et al. 2005) that there is no significant difference of SSA among the Taklimakan and Gobi Desert, where the derived values are about 0.93 . 


\section{Conclusion}

We estimated the spectrally dependent imaginary part of refractive index $\left(n_{\mathrm{i}}\right)$ of Asian dust aerosol in the visible by comparing satellite-observed and simulated TOA reflectances. The approach combines the results obtained from the SeaWiFS ocean color sensor, the vertical profiles provided by CFORS mesoscale transport model, and the size distribution observed concurrently by AERONET sites. Analyses for four dust-prevailed air mass over the Sea of Japan during 2001 and 2002 resulted that the $n_{\text {i value of }}$ Asia dust is about 0.001 at $0.5 \mu \mathrm{m}$ (see Fig. 4 for wavelength dependency). The corresponding averaged coarse-mode dust SSA is found to be $0.98 \pm 0.002$ at $0.555 \mu \mathrm{m}$ (see Fig. 5), indicating that Asian dust particles may cools the Earth. Although the backward trajectories suggest that the four events have different sources, all events show very close

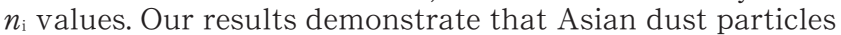
itself is much less absorbing in the visible than previously mentioned.

\section{Acknowledgments}

The authors are grateful to Prof. T. Nakajima at University of Tokyo for providing their Rstar5b code. We also thank Dr. T. Aoki at Meteorological Research Institute and Dr. H. Kobayashi at Univ. of Yamanashi for their helpful advises. We acknowledge Brent Holben, Itaru Sano, all AERONET team for providing Sun photometer measurements, and the SeaWiFS Project for providing SeaWiFS data. This research has been supported by the Grant-in-Aid for Scientific Research in Priority Areas grant 14048213.

\section{References}

Anderson, T. L., S. J. Masonis, D. S. Covert, N. C. Ahlquist, S. G. Howell, A. D. Clarke, and C. S. McNaughton, 2003: Variability of aerosol optical properties derived from in situ aircraft measurements during ACE-Asia. J. Geophys. Res., 108, ACE 15-1 - ACE 15-19.

Aoki, T., T. Y. Tanaka, A. Uchiyama, M. Chiba, M. Mikami, S. Yabuki, and J. R. Key, 2005: Sensitivity experiments of direct radiative forcing caused by mineral dust simulated with a chemical transport model. J. Meteor. Soc. Japan, 83A, 315-331.

Bergstrom, R. W., P. Pilewskie, J. Pommier, M. Rabbette, P. B. Russell, B. Schmid, J. Redemann, A. Higurashi, T. Nakajima, and P. K. Quinn, 2004: Spectral absorption of solar radiation by aerosols during ACE-Asia. J. Geophys. Res., 109, 1-13.

Clarke, A. D., Y. Shinozuka, V. N. Kapustin, S. Howell, B. Huebert, S. Doherty, T. Anderson, D. Covert, J. Anderson, X. Hua, K. G. M. II, C. McNaughton, G. Carmichael, and R. Weber, 2004: Size distributions and mixtures of dust and black carbon aerosol in Asian outflow: Physiochemistry and optical properties. $J$. Geophys. Res., 109, 1-20.

Draxler, R. R., 1996: Trajectory optimization for balloon flight planning. Weather and Forecasting, 11, 111-114

Dubovik, O., A. Smirnov, B. N. Holben, M. D. King, Y. J. Kaufman, T. F. Eck, and I. Slutsker, 2000: Accuracy assessments of aerosol optical properties retrieved from Aerosol Robotic Network (AERONET) Sun and sky radiance measurements. J. Geophys. Res., 105, 9791-9806.

Dubovik, O., B. N. Holben, T. F. Eck, A. Smirnov, Y. J. Kaufman, M. D. King, D. Tanré, and I. Slutsker, 2002: Variability of absorption and optical properties of key aerosol types observed in worldwide locations. J. Atmos. Sci., 59, 590-608.

Fukushima, H., and M. Toratani, 1997: Asian dust aerosol: Optical effect on satellite ocean color signal and a scheme of its correction. J. Geophys. Res., 102, 17119-17130.

Hess, M., P. Koepke, and I. Schult, 1998: Optical properties of aerosols and clouds: The software package OPAC. Bull. Amer. Meteor. Soc., 79, 831-844.

Higurashi, A., and T. Nakajima, 2002: Detection of aerosol types over the East China Sea near Japan from four-channel satellite data. Geophys. Res. Lett., 29, 1836, doi:10.1029/2002GL015357.

Holben, B. N., D. Tanré, A. Smirnov, T. F. Eck, I. Slutsker, N. Abuhassan, W. W. Newcomb, J. S. Schafer, B. Chatenet, F. Lavenu, Y. J. Kaufman, J. V. Castle, A. Setzer, B. Markham, D. Clark, R. Frouin, R. Halthore, A. Karneli, N. T. OAfNeill, C.
Pietras, R. T. Pinker, K. Voss, and G. Zibordi, 2001: An emerging ground-based aerosol climatology: Aerosol optical depth from AERONET. J. Geophys. Res., 106, 12067-12098.

Hooker, S. B., W. E. Esaias, G. C. Feldman, W. W. Gregg, and C. R. McClain, 1992: SeaWiFS Tech. Rep. Ser., Volume1, An overview of SeaWiFS and ocean color. NASA Tech. Memo. 104566, 24pp.

Huebert, B. J., T. Bates, P. B. Russell, G. Shi, Y. J. Kim, K. Kawamura, G. Carmichael, and T. Nakajima, 2003: An overview of ACEAsia: Strategies for quantifying the relationships between Asian aerosols and their climatic impacts. J. Geophys. Res., 108, ACE 1-1 - ACE 1-20.

Kaufman, Y. J., D. Tanré, O. Dubovik, A. Karnieli, and L. A. Remer, 2001: Absorption of sunlight by dust as inferred from satellite and ground-based remote sensing. Geophys. Res. Lett., 28, 1479-1482.

Kim, D.-H., B. J. Sohn, T. Nakajima, and T. Takamura, 2005: Aerosol radiative forcing over east Asia determined from groundbased solar radiation measurements. J. Geophys. Res., 110, 117.

Moulin, C., H. R. Gordon, V. F. Banzon, and R. H. Evans, 2001: Assessment of Saharan dust absorption in the visible from SeaWiFS imagery. J. Geophys. Res., 106, 18239-18250.

Nakajima, T., and M. Tanaka, 1986: Matrix formulations for the transfer of solar radiation in a plane-parallel scattering atmosphere. J. Quant. Spectrosc. Radiat. Transfer, 35, 13-21.

Nakajima, T., 1988: Algorithms for radiative intensity calculations in moderately thick atmospheres using a truncation approximation. J. Quant. Spectrosc. Radiat. Transfer, 40, 51-69.

Nakajima, T., M. Tanaka, M. Yamano, M. Shiobara, K. Arao, and Y. Nakanishi, 1989: Aerosol optical characteristics in the yellow sand events observed in May, 1982 at Nagasaki - Part 2 Models. J. Meteor. Soc. Japan, 67, 279-291.

Nakajima, T. Y., H. Murakami, M. Hori, T. Nakajima, T. Aoki, T. Oishi, and A. Tanaka, 2003: Efficient use of an improved radiative transfer code to simulate near-global distributions of satellite-measured radiances. Applied Optics, 42, 3460-3471.

Patterson, E. M., 1981: Optical properties of the crustal aerosol: relation to chemical and physical characteristics. J. Geophys. Res., 86, 3236-3246.

Pollack, J. B., and J. N. Cuzzi, 1980: Scattering by nonspherical particles of size comparable to a wavelength: A new semiempirical theory and its application to tropospheric aerosols. J. Atmos. Sci., 37, 868-881.

Quinn, P. K., D. J. Coffman, T. S. Bates, E. J. Welton, D. S. Covert, T. L. Miller, J. E. Johnson, S. Maria, L. Russell, R. Arimoto, C. M. Carrico, M. J. Rood, and J. Anderson, 2004: Aerosol optical properties measured on board the Ronald $\mathrm{H}$. Brown during ACE-Asia as a function of aerosol chemical composition and source region. J. Geophys. Res., 109, 1-28.

Shettle, E. P., and R. W. Fenn, 1979: Models for the aerosols fo the lower atmosphere and the effects of humidity variations on their optical properties. AFGL-TR-79-0214, Air Force Geopys. Lab., $94 \mathrm{pp}$

Shimizu, A., N. Sugimoto, I. Matsui, K. Arao, I. Uno, T. Murayama, N. Kagawa, K. Aoki, A. Uchiyama, and A. Yamazaki, 2004: Continuous observations of Asian dust and other aerosols by polarization lidars in China and Japan during ACE-Asia. J. Geophys. Res. 109, 1-14.

Trochkine, D., Y. Iwasaka, A. Matsuki, M. Yamada, Y.-S. Kim, T. Nagatani, D. Zhang, G.-Y. Shi, and Z. Shen, 2003: Mineral aerosol particles collected in Dunhuang, China, and their comparison with chemically modified particles collected over Japan. J. Geophys. Res., 108, ACE 10-1 - ACE 10-11.

Uchiyama, A., A. Yamazaki, H. Togawa, J. Asano, and G. Shi, 2005: Single scattering albedo of aeolian dust as inferred from skyradiometer and in situ ground-based measurement. SOLA, 1 , 209-212.

Uno, I., G. R. Carmichael, D. G. Streets, Y. Tang, J. J. Yienger, S. Satake, Z. Wang, J. Woo, S. Guttikunda, M. Uematsu, K. Matsumoto, H. Tanimoto, K. Yoshioka, and T. Iida, 2003: Regional chemical weather forecasting system CFORS: Model descriptions and analysis of surface observations at Japanese island stations during the ACE-Asia experiment. J. Geophys. Res., 108, 8668, doi:10.1029/2002JD002845.

WMO, 1983: Radiation commission of IAMAP meeting of experts on aerosol and their climate effects. WCP-55, Williamsburg VA, 28-30.

Zhou, M. Y., K. Okada, F. Qian, P.-M. Wu, L. Su, B. E. Casareto, and T. Shimohara, 1996: Characteristics of dust-storm particles and their long-range transport from China to Japan-Case studies in April 1993. Atmos. Res., 40, 19-31.

Manuscript received 15 April 2006, accepted 4 July 2006

SOLA: http://www.jstage.jst.go.jp/browse/sola/ 